\title{
Uniformity of Strawberry Yield and Incidence of Botrytis Fruit Rot in an Annual Production System
}

\author{
S. J. MacKenzie, University of Florida, Gulf Coast Research and Education Center, Dover 33527; C. L. Xiao, \\ Washington State University, Tree Fruit Research and Extension Center, Wenatchee 98801; J. C. Mertely and C. K. \\ Chandler, University of Florida, Gulf Coast Research and Education Center, Dover; F. G. Martin, University of \\ Florida, Department of Statistics, Gainesville 32611; and D. E. Legard, University of Florida, Gulf Coast Research \\ and Education Center, Dover
}

\begin{abstract}
MacKenzie, S. J., Xiao, C. L., Mertely, J. C., Chandler, C. K., Martin, F. G., and Legard, D. E. 2003. Uniformity of strawberry yield and incidence of Botrytis fruit rot in an annual production system. Plant Dis. 87:991-998.

A plant yield and disease incidence uniformity trial was conducted to provide information concerning the efficiency and precision of field trials used to evaluate Botrytis fruit rot control methods on strawberry. Fruit yield and Botrytis fruit rot incidence were recorded for individual strawberry plants of cultivars Sweet Charlie and Camarosa grown in an annual production system over two growing seasons. A nested analysis of variance model was used to measure plot edge effects and to obtain variance components to describe the relationship between plot size and plot variance. Mean seasonal yield for Sweet Charlie was $599 \mathrm{~g} / \mathrm{plant}$ and for Camarosa $972 \mathrm{~g} /$ plant. Mean seasonal fruit rot incidence was $10.3 \%$ for Sweet Charlie and $3.0 \%$ for Camarosa. Plants growing on the edge of plots next to aisles had higher yields (637 versus 577 g/plant for Sweet Charlie and 1047 versus $923 \mathrm{~g} /$ plant for Camarosa), but there was no edge effect for disease incidence. Smith's equation was used to determine the relationship between plot size and plot variance within mulched beds. Smith's index was relatively high for yield (0.92 and 0.95) and Botrytis fruit rot incidence (0.91 and 0.69) for Sweet Charlie and Camarosa, respectively. This suggests a relatively uniform distribution of seasonal yield and disease incidence among plants within beds. Using plot variances estimated from Smith's equation, the power of hypothesis tests to discriminate hypothetical treatment effects of different magnitudes was examined for each cultivar. Power analysis suggests that treatment effects ranging from 11.3 to $21.3 \%$ of the mean seasonal yield observed for Sweet Charlie and 8.6 to $16.5 \%$ of the mean seasonal yield observed for Camarosa can be detected with a power of 0.80 using four replicates of each treatment group and plot sizes ranging from 32 to eight plants/plot. For Botrytis fruit rot incidence, a power of 0.80 is achieved with treatment differences ranging from 24.9 to $44.1 \%$ of mean seasonal Botrytis fruit rot incidence for Sweet Charlie and from 44.1 to $64.9 \%$ of the mean observed for Camarosa using plot sizes ranging from 32 to 8 plants/plot. Before planting, the crown diameter and leaf number of transplants were recorded. There was no consistent significant correlation between any of these growth traits and seasonal yields or Botrytis fruit rot incidence. However, there was a consistent positive correlation for both cultivars between yield and crown diameter and also yield and leaf number during the months of December and January in the early part of the season $(0.151 \leq r \leq 0.314$ for crown diameter and $0.106 \leq r \leq 0.264$ for leaf number).
\end{abstract}

Additional keywords: border effect, Fragaria $\times$ ananassa, gray mold

One of the primary goals of strawberry disease management programs is to control Botrytis fruit rot, which causes fruit losses as high as $35 \%$ in untreated plots in Florida $(16,18)$. This disease is caused by the fungal pathogen Botrytis cinerea and infection occurs primarily at the flower stage of fruit development $(11,12,23,26)$.

Corresponding author: S. J. MacKenzie

E-mail: SMackenzie@ifas.ufl.edu

Florida Agricultural Experiment Station Journal Series No. R-09576.

Accepted for publication 14 April 2003.

Publication no. D-2003-0616-02R

(c) 2003 The American Phytopathological Society
Lesions usually develop after the fruit begins to ripen and may not appear until after the fruit has been packed and shipped (28). In Florida, weekly applications of fungicides such as captan or thiram in conjunction with bloom applications of iprodione or fenhexamid are effective against both preharvest and postharvest infections $(15,18)$. Growers also employ cultural methods to control the disease. Plant spacing may be increased to produce conditions less favorable for Botrytis fruit rot (17) or senescent foliage removed to reduce inoculum (22). These cultural methods, however, have only limited effectiveness. Cultivars also vary in their susceptibility to Botrytis fruit rot and the use of resistant cultivars can substantially reduce disease incidence (17).
Although new cultural and chemical practices to control Botrytis fruit rot are constantly being investigated, little is known about the efficiency of field trials used to evaluate treatment effects on disease incidence and marketable yield, two variables commonly used to evaluate disease control programs. In Florida, strawberry fruit are produced in an annual hill culture system (4). In this system, strawberry plants are grown on plastic-mulched, raised beds that have been fumigated for nematode, disease, and weed control. Clonally propagated transplants are set from late September to early November and fruit is harvested from late November to April. The plants are equally spaced in two staggered rows per bed, with fertilizer and water supplied by drip irrigation. Experiments examining treatment effects on the incidence of Botrytis fruit rot and marketable yields in this cultural system typically measure effects on plots within beds using a randomized block design $(17,18)$. The plot size used in experimental trials affects the variance of plot data, although the exact relationship between plot size and variance must be determined empirically $(27,35)$.

The empirical relationship between plot size and variance can be described by Smith's equation, which takes into account field properties that may influence plot variance by means of a statistic known as Smith's index of soil heterogeneity $(25,27)$. Smith's index of soil heterogeneity is a measure of correlation between adjacent plots and ranges in value from 0 to 1 . Larger values of the index are indicative of a low degree of correlation between plots and a uniform distribution of the variable being measured. Smith's equation can be estimated by regressing the logarithm of the variance for plots of different sizes against the logarithm of the plot size. Once the parameters in Smith's equation have been estimated, the expected variance can be calculated for plots of different sizes and used to examine the efficiency of hypothesis tests examining treatment effects using different combinations of plot size and replication number in the experimental design (6).

Plots used in experiments investigating treatment effects on yield or disease incidence often are separated by open buffer 
areas to facilitate harvesting and to reduce drift from sprayed treatments. These spaces may cause plants on the outer edge of plots to have higher yields because plant-to-plant competition for nutrients is reduced for plants in this position. This has been described as a border or edge effect $(1,9)$. It also is conceivable that plant position within a plot could influence disease development. Microclimate effects have been cited as a potential cause of higher disease incidence with plants grown at narrow spacings $(3,17)$. Similarly, differences in climatic variables could alter disease incidences among plants growing at different locations within plots. Knowledge of the magnitude of edge effects is important when designing experiments where an edge-treatment interaction is likely to occur (35).

Although strawberry plants are propagated clonally, there can be substantial variation in growth attributes (i.e., crown size, fresh weight, leaf number, and so on) among transplants used to establish fruit production fields (30). Variation in growth attributes may affect the yield and timing of fruit production. In perennial strawberry cropping systems, plants with greater mass when transplanted are more likely to flower in the first year and have higher yields $(10,21)$. Also, transplant leaf area is correlated with fruit yield (29). Little is known about similar correlations for strawberries grown in subtropical annual production regions like Florida.

One of the primary goals of this study was to determine the relationship between plot size and variance for plants growing within plastic-mulched beds and to create charts showing the estimated power of hypothesis tests comparing means for treatments conducted with varying plot sizes. In addition, the study was designed to determine the effect of plant position within plots on plant yield and disease incidence. Growth characteristics of individual plants were measured just before transplanting. These measurements were used to examine correlations between growth attributes and overall marketable yield, overall incidence of Botrytis fruit rot, and yields calculated at monthly intervals. Identification and quantification of factors contributing to variation in the incidence of Botrytis fruit rot and yield for strawberry should facilitate experimental design and evaluation of conclusions from published studies.

\section{MATERIALS AND METHODS}

Field preparation and plot configuration. Field experiments were conducted at the University of Florida Gulf Coast Research and Education Center in Dover during the 1997-98 and 1998-99 seasons. Land preparation for each season was begun in September with a broadcast application of a 6:2:8 (N:P:K) starter fertilizer $(570 \mathrm{~kg} / \mathrm{ha})$ and rotovation.
Raised beds measuring $71 \mathrm{~cm}$ wide, $15 \mathrm{~cm}$ high at the edge, and $18 \mathrm{~cm}$ high in the center were shaped, fumigated with methyl bromide/chloropicrin (98:2) at $350 \mathrm{~kg} / \mathrm{ha}$, and covered with black plastic mulch over drip irrigation tape. The distance between bed centers was $1.22 \mathrm{~m}$. Green-top, bareroot strawberry transplants from Canadian nurseries were transplanted into beds in mid-October and irrigated by overhead sprinklers for 10 to 14 days to facilitate establishment. After the plants were established, water and fertilizer were provided twice weekly through drip tape. Freeze and frost protection was provided by overhead sprinklers when necessary.

Plants of cv. Sweet Charlie were set on 7 October for the 1997-98 season and on 23 October for the 1998-99 season in two rows spaced $30.5 \mathrm{~cm}$ apart within a single bed. The bed was divided into four blocks, each containing four plots consisting of two parallel rows with five plants in each row. Plants within each row were separated by $37.5 \mathrm{~cm}$ of open space; plots within blocks and blocks within the bed were separated by $112 \mathrm{~cm}$ of open space. Plant positions within a plot were classified as end, middle, or center. The four plants at the two ends of each plot were classified as end plants. The two plants in the very center of the plot were classified as center plants and the four plants between end and center plants were classified as middle plants.

During 1998-99, plants of cv. Camarosa also were evaluated using the same row and plant spacings and configuration of plots and blocks as used for Sweet Charlie. However, the experiment was planted on two beds and each bed contained only two blocks. Transplants of Camarosa were planted on 23 October.

Data collection. Fruit was harvested twice weekly from 3 December to 30 March (1997-98) or from 10 December to 25 March (1998-99) for Sweet Charlie, and from 18 December to 2 April (199899) for Camarosa. Data from each harvest were recorded for each plant individually. All fruit were counted and sorted based on marketability criteria. Fruit were categorized as unmarketable if they had Botrytis fruit rot or other cull characteristics, including odd shape, small size $(<10 \mathrm{~g})$, or the presence of diseases other than Botrytis fruit rot. Only marketable fruit were weighed. The percent incidence of Botrytis fruit rot was calculated as the number of fruit with Botrytis fruit rot divided by the total number of marketable and unmarketable fruit. Disease incidence data were transformed before analysis using the arcsine-square root transformation to stabilize variance and to normalize the data distribution (2,5). Both monthly and season marketable yield totals were used for analysis; whereas, for disease incidence, only season totals were used.

Estimation of variance components and position effect. Statistical analysis was performed using the SPSS statistical software package (SPSS Inc., Chicago). A nested analysis of variance (ANOVA) model was used to obtain variance components and to test position effects for individual plant yields and Botrytis fruit rot incidence totaled over the full season (24). The model was fitted using the least squares method. Data for Sweet Charlie from the 1997-98 and 1998-99 seasons were analyzed within the same ANOVA model. Effects included in the model were season, block(season), plot(block(season)), and position (the location of the plant within the plot). The residual mean square error for this model is the among-plant variance. For Camarosa, the dependent variables marketable fruit weight and transformed Botrytis fruit rot incidence were modeled using effects bed, block(bed), plot(block(bed)), and position, with the residual mean square error for the model being the among-plant variance. All effects were categorized as random except the fixed effect, position. Mean comparisons for plants growing at different plot positions were made using Fisher's protected least significant difference (LSD, $\alpha$ $=0.05$ ).

Smith's index. Due to correlation between plants based on their proximity to one another, measurements of variance for plots are typically greater than would be expected from measurements of variance for individual plants. Smith's equation adjusts for this correlation when estimating variances for different plot sizes. Smith's equation, $V_{x}=V / x^{b}$, was used to describe the empirical relationship between plot variance and plot size, where $V_{x}=$ the within-bed variance for plots of size $x$ in terms of the smallest unit measured (one plant), $V$ is equal to the within-bed variance of the smallest unit measured (one plant), and $b$ is Smith's index of soil heterogeneity (27). The linearized form of this equation is $\ln \left(V_{x}\right)=\ln (V)-\operatorname{bln}(x)$. Values of $V_{x}$ were calculated from the ANOVA variance components for Sweet Charlie and Camarosa. The parameters $V$ and $b$ were estimated using weighted regression to account for the reduced precision of variance estimates for larger plot sizes. The equations used to obtain weighted regression estimates of $V_{x}$ and $b$ have been reported $(7,31)$. Variance attributed to the position of plants within the plot is not included in calculations for $V_{x}$ because this effect would be correlated between plots.

Power analysis. The power of a hypothesis test is the probability that the null hypothesis is rejected in favor of an alternate hypothesis, given that the alternate hypothesis is true (24). When two treatment means are compared, the power of the hypothesis test is affected by the size of the difference between the means, the variance of the estimated difference between means, and the decision rule used to 
reject the null hypothesis. To determine the effect of different plot sizes on the power of hypothesis tests examining yield and disease incidence, power analysis was performed using the Power and Precision software package (Biostat Inc., Englewood, NJ). The among-plot variance estimates for plots containing different numbers of plants were derived using Smith's equation with no adjustment for finite sample size (31). Graphs were created to show the power of hypothesis tests contrasting two hypothetical treatments with four replications having 8,16 , or 32 plants/plot. Power was calculated for hypothesis tests comparing treatment differences ranging from 0 to $100 \%$ of mean yields and mean Botrytis fruit rot incidences observed in the current study at intervals of $2.5 \%$. The risk of a type I error $(\alpha)$ was set to 0.05 . The analysis assumed a $t$ distribution having 15 degrees of freedom (df). Typically, experiments to investigate Botrytis fruit rot control measures include an array of treatment programs $(14,17,18,22)$. Fifteen degrees of freedom were chosen for the $t$ distribution because it is the number associated with the residual error term for a hypothetical experiment having six treatments and four blocks. Six treatments would be a relatively small number of treatments in an experiment evaluating Botrytis control methods in annual strawberries. Plots of power versus treatment differences were produced by the cubic spline method using GraphPad Prizm (GraphPad Software Inc., San Diego, CA).
Marketable yield variance. One of the initial goals of conducting a uniformity trial with strawberry was to determine if variances in yield were comparable between cultivars at different times in the season. The mean and standard deviation for individual plant marketable yields are reported for monthly intervals. From these data, it was clear that variability in yield is correlated with mean yield and that, over monthly intervals, yields are not the same for the different cultivars. Therefore, to compare variance estimates between cultivars, monthly variance was modeled as a function of the covariate monthly mean and the fixed effect cultivar. Botrytis fruit rot incidence data were not analyzed over monthly intervals due to large variations in fruit produced per plant over these short time periods. Normalization and variance stabilization of incidence data using the arcsine-square root transformation assumes that proportions are calculated from approximately equal sample sizes $(2,5)$, an assumption met only over longer time intervals in this study.

Correlation with transplant growth characteristics. In order to determine the effect of variation in plant growth attributes on variation in yield and incidence of Botrytis fruit rot, the fresh weight, crown diameter, and leaf number of each plant were recorded at the time of transplanting. Pearson correlation values were calculated to describe the relationship between marketable weight of harvested fruit and crown diameter; fruit weight and leaf number; incidence of Botrytis fruit rot and crown diameter; and incidence of Botrytis fruit rot and leaf number. Marketable yield correlations were calculated for both monthly and seasonal intervals. Correlations of plant attributes with incidence of Botrytis fruit rot were calculated only for the full season due to the large variation in fruit produced per plant over short intervals. Crown diameter and fresh weight were highly correlated; therefore, correlations with fruit yield and disease incidence for only one of these variables, crown diameter, are reported.

\section{RESULTS}

Harvest overview. During the 1997-98 season, the mean incidence of Botrytis fruit rot for cv. Sweet Charlie was $12.4 \%$ and mean marketable yield per plant was 708 g. During the 1998-99 season, Sweet Charlie had less Botrytis fruit rot $(8.1 \%)$ and produced lower yields (490 g/plant). The differences in yield and fruit rot between seasons were significant (Table 1). Early in the 1997-98 season, 16 Sweet Charlie plants $(10 \%$ of the total in that season) died due to Phytophthora crown rot. Data from these plants were excluded from the analysis. In the 1998-99 season, Camarosa yielded an average of $972 \mathrm{~g}$ of marketable fruit per plant and Botrytis fruit rot incidence was $3.0 \%$. Both cultivars produced the majority of their fruit late in the season, during the months of February and March.

Table 1. Analysis of variance (ANOVA) for total marketable yield and incidence of Botrytis fruit rot for 'Sweet Charlie' and 'Camarosa' strawberry plants during the 1997-98 and 1998-99 seasons at Dover, FL ${ }^{\mathrm{y}}$

\begin{tabular}{|c|c|c|c|c|c|}
\hline Variable, cultivar, source ${ }^{\mathrm{z}}$ & df & Mean square & $\boldsymbol{F}$ & $P>F$ & Expected mean square \\
\hline \multicolumn{6}{|l|}{ Marketable yield } \\
\hline \multicolumn{6}{|l|}{ Sweet Charlie } \\
\hline Season & 1 & $3,673,815$ & 108.83 & 0.000 & $150.34 \sigma_{\text {season }}^{2}+37.59 \sigma_{\text {block(season) }}^{2}+9.40 \sigma_{\text {plot(block(season) })}^{2}+\sigma_{\text {plant }}^{2}$ \\
\hline Block(Season) & 6 & 33,809 & 1.19 & 0.344 & $37.79 \sigma_{\text {block(season) }}^{2}+9.45 \sigma_{\text {plot(block(season)) }}^{2}+\sigma_{\text {plant }}^{2}$ \\
\hline Plot(Block(Season)) & 24 & 28,414 & 1.19 & 0.254 & $9.48 \sigma_{\text {plot(block(season)) }}^{2}+\sigma_{\text {plant }}^{2}$ \\
\hline Position & 2 & 136,984 & 5.72 & 0.004 & $96.83 \Sigma \alpha_{\text {position }}^{2} / 2+\sigma_{\text {plant }}^{2}$ \\
\hline Plant & 270 & 23,965 & $\ldots$ & $\ldots$ & $\sigma_{\text {plant }}^{2}$ \\
\hline \multicolumn{6}{|l|}{ Camarosa } \\
\hline Bed & 1 & 740,384 & 29.47 & 0.032 & $80 \sigma_{\text {bed }}^{2}+40 \sigma_{\text {block(bed) }}^{2}+10 \sigma_{\text {plot(block(bed) })}^{2}+\sigma_{\text {plant }}^{2}$ \\
\hline $\operatorname{Block}(\mathrm{Bed})$ & 2 & 25,125 & 0.44 & 0.656 & $40 \sigma_{\text {block(bed) }}^{2}+10 \sigma_{\text {plot(block(bed) })}^{2}+\sigma_{\text {plant }}^{2}$ \\
\hline Plot(Block(Bed)) & 12 & 57,564 & 1.42 & 0.164 & $10 \sigma_{\text {plot(block(bed) })}^{2}+\sigma_{\text {plant }}^{2}$ \\
\hline Position & 2 & 297,559 & 7.33 & 0.001 & $51.2 \sum \alpha_{\text {position }}^{2} / 2+\sigma_{\text {plant }}^{2}$ \\
\hline Plant & 142 & 40,584 & $\ldots$ & $\ldots$ & $\sigma_{\text {plant }}^{2}$ \\
\hline \multicolumn{6}{|l|}{ Incidence of Botrytis } \\
\hline \multicolumn{6}{|l|}{ Sweet Charlie } \\
\hline Season & 1 & 0.4359 & 43.74 & 0.001 & $150.34 \sigma_{\text {season }}^{2}+37.59 \sigma_{\text {block(season) }}^{2}+9.40 \sigma_{\text {plot(block(season)) }}^{2}+\sigma_{\text {plant }}^{2}$ \\
\hline Block(Season) & 6 & 0.0100 & 0.66 & 0.681 & $37.79 \sigma_{\text {block(season) }}^{2}+9.45 \sigma_{\text {plot(block(season) })}^{2}+\sigma_{\text {plant }}^{2}$ \\
\hline Plot(Block(Season)) & 24 & 0.0151 & 1.49 & 0.070 & $9.48 \sigma_{\text {plot(block(season) })}^{2}+\sigma_{\text {plant }}^{2}$ \\
\hline Position & 2 & 0.0002 & 0.02 & 0.982 & $96.83 \sum \alpha_{\text {position }}^{2} / 2+\sigma_{\text {plant }}^{2}$ \\
\hline Plant & 270 & 0.0101 & $\ldots$ & $\ldots$ & $\sigma_{\text {plant }}^{2}$ \\
\hline \multicolumn{6}{|l|}{ Camarosa } \\
\hline Bed & 1 & 0.0012 & 0.20 & 0.698 & $80 \sigma_{\text {bed }}^{2}+40 \sigma_{\text {block(bed) }}^{2}+10 \sigma_{\text {plot(block(bed) })}^{2}+\sigma_{\text {plant }}^{2}$ \\
\hline Block(Bed) & 2 & 0.0060 & 0.49 & 0.624 & $40 \sigma_{\text {block(bed) }}^{2}+10 \sigma_{\text {plot(block(bed) })}^{2}+\sigma_{\text {plant }}^{2}$ \\
\hline Plot(Block(Bed)) & 12 & 0.0122 & 2.90 & 0.001 & $10 \sigma_{\text {plot(block(bed)) }}^{2}+\sigma_{\text {plant }}^{2}$ \\
\hline Position & 2 & 0.0036 & 0.87 & 0.423 & $51.2 \sum \alpha_{\text {position }}^{2} / 2+\sigma_{\text {plant }}^{2}$ \\
\hline Plant & 142 & 0.0042 & $\ldots$ & $\ldots$ & $\sigma_{\text {plant }}^{2}$ \\
\hline
\end{tabular}

${ }^{y}$ ANOVA for incidence of Botrytis fruit rot was performed on arcsine-square root transformed data. Data for Camarosa were collected for the 1998-99 season only.

${ }^{\mathrm{z}}$ Dependent variable, cultivar, and source of variation. Position refers to location within a 10-plant plot consisting of two rows with 5 plants each. The Four plants on the ends are in the end position. The two plants in the center of the plot are in the center position and the four plants between the center and the end are in the middle position. 
Analysis of variance. Data collected for Sweet Charlie during the 1997-98 and 1998-99 seasons was initially examined using separate ANOVA models. A comparison of the among-plant variance for Botrytis fruit rot incidence in these seasons indicated that the variance estimates were not significantly different $(F=$ 1.12 , df $=142$ and 126; $P=0.452$ ); however, among-plant variance was higher for marketable yield in 1997-98 $(F=1.44$, df $=126$ and 142; $P=0.04)$. Although there was a modest difference in among-plant variance between seasons for marketable yield, data from both seasons were analyzed at the same time using an ANOVA model that included the random variable season. ANOVA models are relatively robust against unequal variances when sample sizes are approximately equal (24) and no distortion of block or plot variance component estimates were observed when data sets were combined. There were no season-position interactions for either disease incidence or yield; therefore, this effect was not included in the final model. Effects included in the final reduced model are found in Table 1.

There were no significant plot or block effects for marketable yield for either Sweet Charlie or Camarosa, suggesting that environmental variation contributing to variation in yield is uniformly distributed within a bed (Table 1). For Camarosa, there was a significant bed effect $(P=$ 0.032). No bed effect was measured for Sweet Charlie because all plots of this cultivar were set in a single bed each season. A comparison of means for plants growing in different positions within the plot indicated that plants on the ends of plots had significantly higher yields than plants at other positions for both cultivars (Table 2).

There was no significant effect of bed or block on incidence of Botrytis fruit rot for either cultivar; however, there was a significant plot effect on fruit rot incidence for Camarosa and Sweet Charlie $(P=0.01$ and 0.07 , respectively), suggesting an uneven distribution of disease within the bed (Table 1). Plant position did not have a significant effect on the incidence of Botrytis fruit rot (Tables 1 and 2).

The residual among-plant variance for transformed incidence of Botrytis fruit rot for Sweet Charlie was estimated to be 0.0101 . This was higher than what would be predicted for among-plant variance based on the number of fruit examined from each plant. The variance for the arcsine-transformed proportion of disease incidence of individual plants should be equivalent to $1 /(4 n)$ under the assumption that disease is randomly distributed among plants, where $n$ is equal to the number of fruit harvested (5). Deviations from this value would indicate that the probability of a fruit getting disease is different between plants growing within the same plot. An average of 76.4 and 43.4 fruit were produced during the 1997-98 and 1998-99 seasons, respectively. For these seasons, expected residual variance would be 0.0033 and 0.0058. Camarosa produced an average of 65.8 fruit per plant with an expected residual among-plot variance of 0.0038 , similar to the observed value of 0.0042 .

Estimation of $V, b$, and power analysis. Values for individual variance components derived from the analysis in Table 1

Table 2. Mean marketable yield and incidence of Botrytis fruit rot for 'Sweet Charlie' and 'Camarosa' strawberry plants at defined plot positions ${ }^{\mathrm{x}}$

\begin{tabular}{lcrrrr}
\hline & \multicolumn{2}{c}{ Marketable yield (g/plant) } & & \multicolumn{2}{c}{ Botrytis fruit rot incidence $^{\mathbf{y}}$} \\
\cline { 2 - 3 } \cline { 5 - 6 }${\text { Position in } \text { plot }^{\mathbf{z}}}$ & Sweet Charlie & Camarosa & & Sweet Charlie & Camarosa $^{\text {End }}$ \\
Middle & $637.09 \mathrm{a}$ & $1,046.73 \mathrm{a}$ & & $10.04(0.311) \mathrm{a}$ & $2.86(0.159) \mathrm{a}$ \\
Center & $571.59 \mathrm{~b}$ & $916.48 \mathrm{~b}$ & & $10.21(0.313) \mathrm{a}$ & $3.30(0.171) \mathrm{a}$ \\
\cline { 6 - 7 } & $586.69 \mathrm{~b}$ & $936.44 \mathrm{~b}$ & & $10.24(0.312) \mathrm{a}$ & $2.55(0.155) \mathrm{a}$ \\
\hline
\end{tabular}

${ }^{x}$ Means followed by different letters within a column are significantly different as determined by Fisher's protected least significant difference test $(P<0.05)$. Means reported for Sweet Charlie were calculated over two years.

${ }^{\mathrm{y}}$ Mean value for arcsine-transformed disease incidence data is reported in parentheses.

${ }^{\mathrm{z}}$ Position refers to location within a 10-plant plot consisting of two rows with 5 plants each. The four plants on the ends are in the end position. The two plants in the center of the plot are in the center position and the four plants between the center and end plants are in the middle position.

Table 3. Parameter estimates for Smith's equation for the variables marketable yield and incidence of Botrytis fruit rot for 'Sweet Charlie' and 'Camarosa' strawberry grown at Dover, FL ${ }^{\mathrm{z}}$

\begin{tabular}{lcccccccc}
\hline & \multicolumn{3}{c}{ Marketable yield (g/plant) } & & \multicolumn{3}{c}{ Arcsine(sqrt(percent Botrytis/100)) } \\
\cline { 2 - 4 } Cultivar & $\boldsymbol{V}$ & $\boldsymbol{b}$ & $\mathbf{S E ~ o f ~} \boldsymbol{b}$ & & $\boldsymbol{V}$ & $\boldsymbol{b}$ & SE of $\boldsymbol{b}$ \\
\hline Sweet Charlie & $24,516.79$ & 0.92 & 0.10 & & 0.01047 & 0.91 & 0.10 \\
Camarosa & $41,314.70$ & 0.95 & 0.14 & & 0.00471 & 0.69 & 0.13 \\
\hline
\end{tabular}

${ }^{\mathrm{z}}$ Smith's equation is $V_{x}=V / x^{\mathrm{b}}$, where $V_{x}=$ the theoretical among-plot variance of plots containing $x$ plants, $V$ is the variance of plots containing one plant, and $b$ is Smith's index of soil heterogeneity. The equation assumes that yields from plots are expressed in units of average yield per plant. SE = standard error. were used to determine variances of hypothetical plots containing different numbers of plants. The values for parameters in Smith's equation were estimated from these plot variances using the weighted regression technique of Hatheway and Williams (7). Estimates of $V$ and $b$ for marketable yield and Botrytis fruit rot incidence are reported in Table 3. These parameters are based on within-bed variance components for Camarosa or, in the case of Sweet Charlie, within-season variance components, which are equivalent to within-bed variance components because Sweet Charlie was grown in only one bed in each of two successive seasons and Camarosa in two beds during the same season.

The power of hypothesis tests comparing two hypothetical treatments having four replications and 8,16 , or 32 plants/plot are shown in Figure 1. The values of $V$ and $b$ reported in Table 3 were used to calculate the plot variances required for this power analysis. For Sweet Charlie yield data, the null hypothesis that there are no differences between treatments will be rejected $80 \%$ of the time with treatment differences ranging from 67.4 to $127.5 \mathrm{~g} / \mathrm{plant}$, depending on the number of plants per plot. This range is equivalent to 11.3 to $21.3 \%$ of the grand mean observed over the two seasons Sweet Charlie was grown. For Camarosa yield data, a power of 0.80 is achieved with treatment differences ranging from 83.1 to 160.5 $\mathrm{g} / \mathrm{plant}$, which is equivalent to 8.6 to $16.5 \%$ of the mean observed for Camarosa over the one season in which the cultivar was grown. For incidence of Botrytis fruit rot, a power of 0.80 was observed, with differences in disease incidence ranging from 2.56 to $4.53 \%$ for Sweet Charlie and 1.31 to $1.93 \%$ for Camarosa. These differences are equivalent to 24.9 to $44.1 \%$ of the grand mean disease incidence observed for Sweet Charlie over two seasons and 44.1 to $64.9 \%$ of the mean for Camarosa.

Variance of monthly marketable yields. Originally, variances in marketable yield for each month were to be compared between cultivars. However, such comparisons are inappropriate, because average monthly marketable yields are not the same for each cultivar and the standard deviation in marketable yield is correlated with average marketable yield (Table 4). To address this problem, the relationship between mean yield, cultivar, and variance in yield was determined for monthly data using an analysis of covariance model (Table 5). There was a strong linear relationship between mean yield and variance $(P<0.001)$. However, cultivar did not significantly affect variance and there was no significant effect of cultivar-mean yield interaction on variance.

Growth measurement correlations. Fresh plant weight and crown diameter were highly correlated $(0.70 \leq r \leq 0.81)$; 
therefore, only crown diameter was used for the correlation analysis. Significant positive correlations between growth attributes and yield in both years were consistently observed in the early season only (Table 6). During the months of December and January, yield was positively correlated with crown diameter and leaf number $(0.151 \leq r \leq 0.314$ and $0.106 \leq r \leq$ 0.228 , respectively) for both cultivars. Results for the months of February and March were not consistent across seasons. For total seasonal yield, the only statistically significant correlation observed was between Sweet Charlie leaf number and marketable yield during the 1997-98 season $(r=0.266)$. All other correlations were not statistically significant. In 1998-99, there was a significant correlation between crown size and incidence of Botrytis fruit $\operatorname{rot}(r=0.176)$ for Sweet Charlie. No other correlations between vegetative growth characteristics and total Botrytis fruit rot incidence were statistically significant.

\section{DISCUSSION}

ANOVA models examining seasonal data from strawberry were used to determine the effect of plant position within a plot on marketable yield of strawberry and the incidence of Botrytis fruit rot, and to determine the relationship between plot size and plot variance for these variables. Marketable yields of individual plants were significantly affected by their location within a plot, with plants next to aisles (unplanted areas) producing greater yields. However, there was no effect of plant position within plots on the incidence of Botrytis fruit rot. Measurements of

Table 4. Means and standard deviations of marketable yields of strawberry at defined intervals at Dover, FL

\begin{tabular}{lrc}
\hline & \multicolumn{2}{c}{ Marketable yield (g/plant) } \\
\cline { 2 - 3 } Cultivar, season, harvest period & Mean & Standard deviation \\
\hline Sweet Charlie & & \\
1997-98 & & \\
December & 98.10 & 43.16 \\
January & 86.38 & 56.24 \\
February & 287.31 & 117.61 \\
March & 236.38 & 106.37 \\
December-March & 708.17 & 171.76 \\
1998-1999y & & \\
December & 56.23 & 21.83 \\
January & 85.40 & 42.46 \\
February & 55.36 & 45.60 \\
March & 293.28 & 115.67 \\
December-March & 490.28 & 146.31 \\
Camarosa & & \\
1998-1999y & & \\
December & 46.39 & 25.50 \\
January & 94.19 & 51.20 \\
February & 117.43 & 74.18 \\
March & 586.75 & 167.99 \\
2 April & 127.83 & 55.34 \\
December-2 April & 972.58 & 211.97 \\
\hline
\end{tabular}

${ }^{\mathrm{x}}$ Data collected from 144 plants.

y Data collected from 160 plants.

${ }^{\text {z }}$ Data from the last harvest made on 2 April 1999.
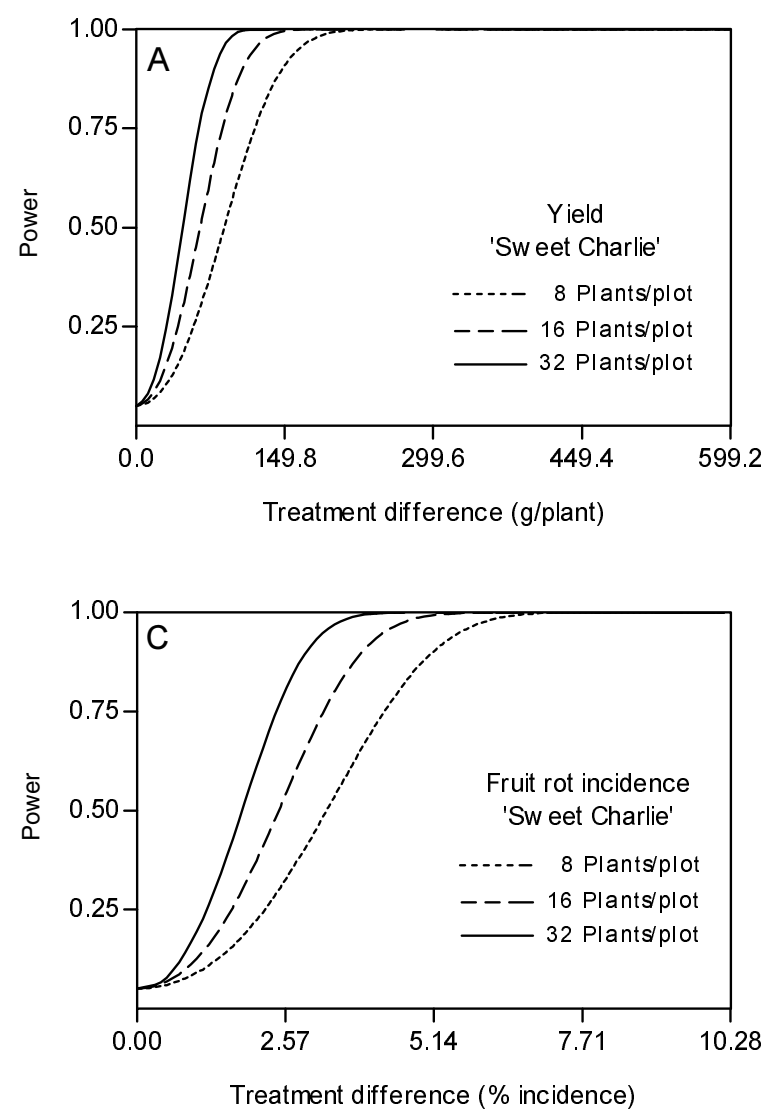
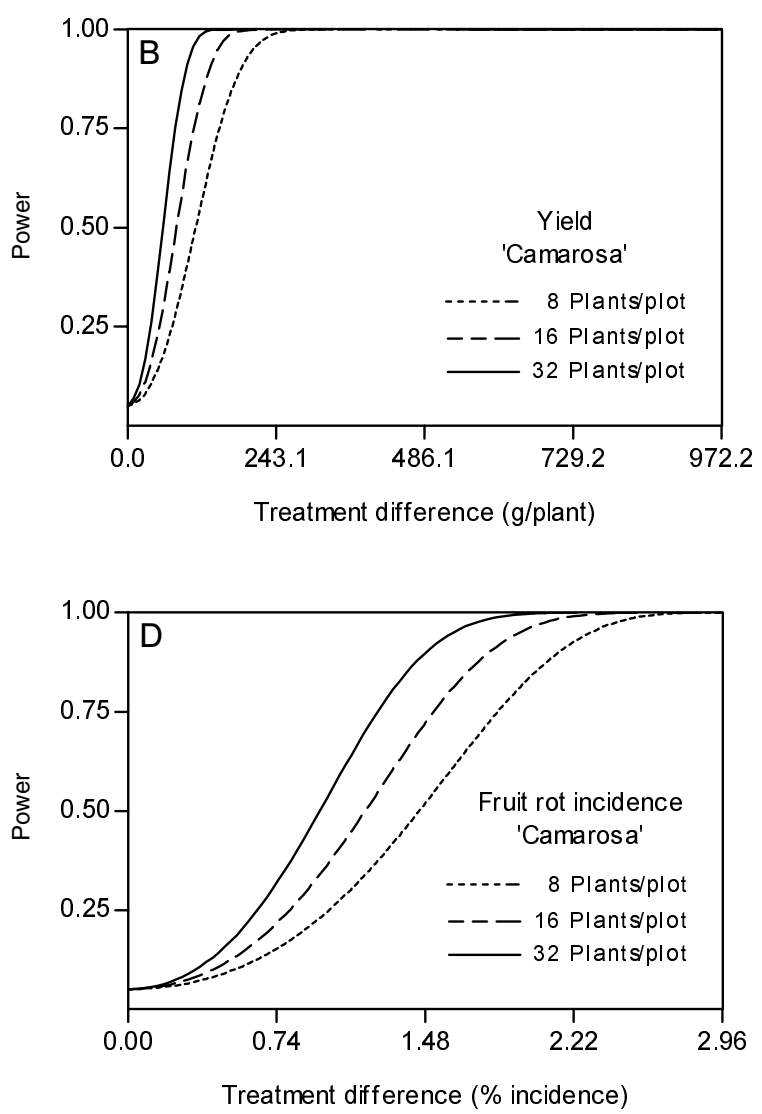

Fig. 1. Graphs showing the power of hypothesis tests comparing two treatment means. Treatment plots have 8 , 16 , or 32 plants/plot and are replicated four times. A and B, Tick marks on the $x$ axis represent differences in marketable yield of strawberries between treatments equivalent to $0,25,50,75$, and $100 \%$ of the grand mean for 'Sweet Charlie' yield over two seasons ( $599.2 \mathrm{~g} / \mathrm{plot})$ and the grand mean for 'Camarosa' yield over one season (972.2 g/plot). C and D, Tick marks on the $x$ axis represent differences in Botrytis fruit rot incidence between treatments equivalent to $0,25,50,75$, and $100 \%$ of the grand mean for Sweet Charlie disease incidence over two seasons (10.26\%) and the grand mean for Camarosa disease incidence over one season (2.97\%). 
heterogeneity indicated that both yield and incidence of Botrytis fruit rot were relatively evenly distributed among plants within beds and that increasing plot size would effectively reduce among-plot variance for these variables. An examination of growth attributes of strawberry transplants revealed that there was a small correlation between leaf number and crown diameter with early-season but not late-season yields. The information provided from this uniformity trial can be used to design experiments to estimate treatment effects consistent with those that would be observed in production fields and to evaluate the efficiency of field experiments investigating methods to control Botrytis fruit rot.

Marketable yields were influenced by the position of plants within the plot because plants grown next to aisles produced higher yields than those in the interior of the plot. This effect usually results from reduced interplant competition for nutrients, light, and moisture for plants growing next to aisles (36), and was evident for both cultivars tested. There was little indication that this effect extends very far into the plot, because there was no difference in yield between plants with one or two plants between them and the aisle. The border effect on marketable yield should be taken into consideration when designing experiments where there may be a significant border-treatment interaction. In particular, experiments to investigate plant spacing may require spaces between plots to be planted or fruit from border plants to be ignored. These steps will make estimates of treatment effects from plot trials more consistent with results observed in commercial production systems (35). There was no border effect on the incidence of Botrytis fruit rot. The lack of a border effect for Botrytis fruit rot may result from plants having sufficient space between them, so that microclimatic differences in border plants are not enough to affect Botrytis fruit rot incidence. In a previous study, it was found that effects of plant spacing on the incidence of Botrytis fruit rot are not obvious when gaps between plants approach those used in the present study (17).

The $b$ values calculated for yield and Botrytis fruit rot within a strawberry bed are relatively large compared with published values for yields from 14 other crops (27). Published $b$ values ranged from 0.05 to 0.80 , with a mean of 0.41 . Only the $b$ estimate for the incidence of Botrytis fruit rot for Camarosa $(b=0.69)$ fell within this range, although it was considerably greater than the mean. The high $b$ values calculated for strawberry yields within beds are probably a result of the raised-bed annual cultural system, because variation

Table 5. Analysis of covariance table showing the effect of mean and cultivar on marketable yield variance measured at monthly intervals for strawberry cultivars Sweet Charlie and Camarosa

\begin{tabular}{lcrrc}
\hline Source of variation & df & Mean square & $\boldsymbol{F}$ & $\boldsymbol{P}>\boldsymbol{F}$ \\
\hline Mean & 1 & $616,084,016.9$ & 585.11 & 0.000 \\
Cultivar & 1 & $81,540.56$ & 0.08 & 0.787 \\
Mean $\times$ cultivar & 1 & $687,931.26$ & 0.65 & 0.440 \\
Error & 9 & $1,052,930.46$ & $\ldots$ & $\ldots$ \\
\hline
\end{tabular}

in yield among plots in a perennial production system has been shown to be relatively insensitive to changes in the number of plants per plot (8). In the annual raised-bed culture system, water and fertilizer are uniformly distributed down the center of beds and plants are distributed the same distance from the nutrient source; thus, yield variation is less likely to result from uneven distribution of plant nourishment or soil heterogeneity. The significant plot effect on disease incidence for Camarosa and Sweet Charlie and the relatively small $b$ estimate for Camarosa disease incidence likely is due to disease gradients produced from an uneven distribution of inoculum sources. Such gradients have been measured for $B$. cinerea causing gray mold on snap beans (13), although correlation in disease incidences between neighboring strawberry plants is likely to be reduced when strawberry disease incidence is calculated from data collected over a longer time interval.

Expected residual variance estimates for incidence of Botrytis fruit rot were determined from the number of fruit harvested under the assumption that disease is randomly distributed among plants. Residual variance for the incidence of Botrytis fruit rot in Sweet Charlie was greater than expected, which is consistent with the aggregation of disease within plants $(20,32)$. Disease aggregation is a common phenomenon and has been described over short sampling intervals for leaf spot and Phomopsis leaf blight of strawberry $(33,34)$. The higher observed variance relative to expected variance, under the assumption that disease is randomly distributed among plants, indicates that designing experiments using expected

Table 6. Correlation between strawberry transplant growth traits and marketable yield or incidence of Botrytis fruit rot for plants grown at Dover, FL

\begin{tabular}{|c|c|c|c|c|}
\hline \multirow[b]{3}{*}{ Season, cultivar, harvest period } & \multicolumn{4}{|c|}{ Pearson's product moment correlation $(\mathbf{r})$} \\
\hline & \multicolumn{2}{|c|}{ Marketable yield ${ }^{\mathrm{z}}$} & \multicolumn{2}{|c|}{ Arcsine(sqrt(percent Botrytis incidence)) } \\
\hline & Crown diameter (mm) & Leaf number & Crown diameter (mm) & Leaf number \\
\hline \multicolumn{5}{|l|}{ 1997-98 } \\
\hline \multicolumn{5}{|l|}{ Sweet Charlie } \\
\hline December & $0.314 * *$ & $0.264 * *$ & $\ldots$ & $\ldots$ \\
\hline January & $0.188^{*}$ & $0.228 * *$ & $\ldots$ & $\ldots$ \\
\hline February & -0.161 & 0.006 & $\ldots$ & $\ldots$ \\
\hline March & $0.179 *$ & $0.195 *$ & $\ldots$ & $\ldots$ \\
\hline December-March & 0.141 & $0.266^{* *}$ & 0.049 & -0.023 \\
\hline \multicolumn{5}{|l|}{ 1998-99 } \\
\hline \multicolumn{5}{|l|}{ Sweet Charlie } \\
\hline December & $0.272 * *$ & 0.121 & $\ldots$ & $\ldots$ \\
\hline January & $0.208^{* *}$ & $0.201 *$ & $\ldots$ & $\ldots$ \\
\hline February & $0.208 * *$ & $0.218 * *$ & $\ldots$ & $\ldots$ \\
\hline March & -0.037 & -0.030 & $\ldots$ & $\ldots$ \\
\hline December-March & 0.136 & 0.120 & $0.176^{*}$ & 0.090 \\
\hline \multicolumn{5}{|l|}{$1998-99$} \\
\hline \multicolumn{5}{|l|}{ Camarosa } \\
\hline December & $0.220 * *$ & 0.106 & $\ldots$ & $\ldots$ \\
\hline January & 0.151 & $0.160^{*}$ & $\begin{array}{l}\cdots \\
\cdots\end{array}$ & $\cdots$ \\
\hline February & $0.385^{* *}$ & $0.201 *$ & $\ldots$ & $\ldots$ \\
\hline March & 0.005 & 0.021 & $\ldots$ & $\ldots$ \\
\hline 2 April & $-0.178^{*}$ & -0.092 & $\ldots$ & $\ldots$ \\
\hline December-2 April & 0.151 & 0.111 & -0.048 & 0.084 \\
\hline
\end{tabular}

${ }^{\mathrm{z}}$ Symbols $*$ and $* *$ indicate significant at $P<0.05$ and 0.01 , respectively. 
treatment variances for incidence determined from the number of fruit to be examined would not produce accurate results. For Camarosa, there was not a large difference between observed and expected variance in the incidence of Botrytis fruit rot. This is unexpected because there was evidence for spatial aggregation of disease from the presence of a significant plot effect and a relatively low $b$ value compared with the observed value for Sweet Charlie. This result may be explained by the overestimation of the expected variance when using arcsine-transformed data with average proportions of less than 5\% (5).

In recent evaluations of treatment effects in annual winter strawberry, the number of plants composing a plot ranged from 18 to 48 and plots were placed on three or four beds $(14,17,18,22)$. Treatments typically were replicated once within each bed, and the effect of bed on yield or disease incidence was included in ANOVA models as a blocking factor. In the current study, simulations were designed to measure the power of hypothesis tests comparing treatment means using a design very similar to those already published. It was assumed that there was a moderate number of treatments included in the trial and that variance due to any bed effect is removed from the residual error term. The numbers of plants per plot chosen for the simulations are representative not only of those used in Botrytis fruit rot control programs but those that have been observed in breeding programs. The power analysis for Botrytis fruit rot incidence estimates that, $80 \%$ of the time, differences between treatments ranging from 24.9 to $44.1 \%$ of the mean fruit rot incidence observed for Sweet Charlie will be detected using four-plot replicates with plot sizes from 32 to 8 plants/plot, respectively. For Camarosa, differences in treatments ranging from 44.1 to $64.9 \%$ of the mean incidence observed in the current study will be detected with four replicates over the same range of plot sizes. For eight-plant plots of Sweet Charlie, this would mean that the incidence of Botrytis would have to be reduced from 10.3 to $5.7 \%$ to achieve a power of 0.80 . For eight-plant plots of Camarosa, disease incidence would have to be reduced from 3.0 to $1.04 \%$ to achieve the same power. Although these differences seem large, it is not uncommon to see effects of this magnitude on disease incidence when evaluating the efficacy of fungicide applications. Fungicides can reduce the incidence of Botrytis fruit rot in strawberry by $50 \%$ and, in some cases, by as much as $90 \%(14,18)$. Such large impacts on disease would be detected even under the relatively low disease pressure observed for Camarosa. However, it may be difficult to find statistically significant differences between fungicide treatment programs that have moderately different levels of efficacy, even though these differences are real and may justify the use of one treatment over another when total field production is taken into consideration. Also, to demonstrate effectiveness, cultural control practices that do not produce large reductions in disease $(17,22)$ may benefit from inclusion of more plants in treatment groups by either increasing the number of plot replications or by increasing the size of plots.

The absolute change in disease incidence required to statistically demonstrate the effectiveness of a control measure was not the same for Sweet Charlie and Camarosa. Sweet Charlie, the cultivar more susceptible to Botrytis fruit rot, required a larger change in disease incidence. This finding indicates that the power of hypothesis tests to detect treatment effects on disease incidence will change under different disease conditions. This results from the effect of the transformation on mean differences and disease variance. Although, at higher levels of disease, larger changes in disease incidence were required to achieve comparable power using statistical tests, the proportionate change in disease incidence actually was less. This suggests that, in experiments in which several treatments are to be evaluated, more susceptible cultivars should be used because potentially more levels of effectiveness can be discriminated.

The power analysis for marketable yield indicates that, $80 \%$ of the time, differences in yield between treatment groups equal to 11.3 to $21.3 \%$ of the overall mean for Sweet Charlie and 8.6 to $16.5 \%$ of the overall mean for Camarosa will be identified correctly as statistically significant using four replicates of 32-, 16-, or 8-plant plots. In an experiment with Sweet Charlie and 32 plants/plot, an $11.3 \%$ change (2.16 $\mathrm{kg} / \mathrm{plot})$ in the overall mean yield (19.18 $\mathrm{kg} / \mathrm{plot}$ ) for Sweet Charlie would be detected with a power of 0.80 . In contrast, with eight-plant plots, a $21.3 \%$ change $(1.02 \mathrm{~kg} / \mathrm{plot})$ in the overall mean yield ( $4.79 \mathrm{~kg} / \mathrm{plot}$ ) for Sweet Charlie should be detected with a power of 0.80 . In a previous study examining strawberry yields in a perennial system, it was estimated that five replicates of 24 plants/plot would give a $50 \%$ chance of detecting a $20 \%$ difference in yields among treatments (8). The greater efficiency of trials using the annual system in Florida may result from the uniform distribution of yield variation among plants in the same bed.

The difference in treatment means required to obtain statistical significance is less for marketable yields than it is for disease incidence when measured as a proportion of the treatment means being investigated. Although the yield changes required to achieve statistical significance appear relatively small, they may be hard to achieve through fungicide applications or cultural practices meant to control Botrytis fruit rot. In untreated control plots, cumulative incidence of Botrytis fruit rot has been measured to be as high as $35 \%$ $(14,18)$. Fruit that develop disease at an early stage of development may not be harvested; therefore, such high disease pressure may reduce cumulative marketable yields by more than $50 \%(14,18)$. At these disease levels, finding significant differences in marketable yield between treated plots and untreated plots is not difficult. However, differences in marketable yield are more difficult to detect when disease pressure is low. During the 199899 season, only $3 \%$ of the fruit from Camarosa was visibly infected with Botrytis spp. Even if a fungicide treatment completely eliminated Botrytis fruit rot, marketable yields would not increase by more than $6 \%$, assuming at least half of infected fruit are harvested in control plots. Although a significant difference in Botrytis fruit rot would likely be detected for this fungicide treatment compared with the control, a significant difference in yield typically would not, because the power of the hypothesis test would be below 0.5 for any plot size commonly used. In essence, it is harder to detect treatment effects on yield than it is to detect treatment effects on disease incidence due to the intrinsic variation in yields and constraints on the effect that fungicide applications can have on yields. As a result, effects of treatment programs that have the ability to increase yields in an economically beneficial manner when measured over an entire field may have a low probability of being detected when mean yields from small plots are used as the criteria for evaluation.

Using Smith's equation, the variance of a treatment mean can be estimated by the formula $V_{\text {mean }}=V /\left(x^{b} r\right)$ with plots of size $x$ replicated $r$ times. In an experiment measuring a variable with a low $b$, assuming the total number of plants used in the experiment remains constant, using fewer replicates in favor of larger plot sizes will increase the variance of mean estimates to a greater extent than if $b$ is close to 1 . Lin and Binns (19) evaluated different experimental designs with a fixed number of plants using a statistic that they referred to as "relative efficiency". The relative efficiency of two designs is measured by taking the ratio of the variance of mean differences between two treatments measured using different designs (variance design $1 /$ variance design 2 ). If the effects of the number of $\mathrm{df}$ from which variance components are estimated are ignored, the relative efficiency of one experimental design versus another reduces to the equation $\left(r_{2} / r_{1}\right)^{1-b}$, with $r_{2}$ equal to the number of replicates in design $2, r_{1}$ equal to the number of replicates in design 1 , and $b$ equal to Smith's index of soil heterogeneity. For strawberry marketable yield, increasing the number of replicates from 4 to 16 would give a ratio of 1.12 for Sweet Charlie and a ratio of 1.07 for Camarosa. 
For disease incidence, increasing replicates from 4 to 16 would give a ratio of 1.13 for Sweet Charlie and 1.53 for Camarosa. Only for the incidence of Botrytis fruit rot on Camarosa does it appear that more replicates would substantially increase the efficiency of experiments, and this increase in efficiency would come at the cost of evaluating four times as many plots. The effect of increasing replication numbers by using smaller plots on the efficiency of hypothesis tests also was examined using power analysis (data not shown). In these simulations, a power of 0.80 was achieved for Camarosa with a reduction in disease incidence from 2.97 to $1.60 \%$ using 16 replications of 4-plant plots as opposed to a reduction in disease incidence from 2.97 to $1.28 \%$ using 4 replications of 16-plant plots. For the other combinations of cultivar and disease incidence, smaller gains were observed. In these simulations, the difference between treatment means at which a power of 0.80 was achieved was reduced by only 9 to $11 \%$. These simulations assumed that treatments being compared were included in a field trial containing six treatments. If fewer than six treatments are included, the effect of using more replications and smaller plot sizes on the power of hypothesis tests would be greater due to changes in the number of $\mathrm{df}$ from which variance components are estimated.

The strong correlation between mean marketable yield and yield variance at monthly intervals was not different between cultivars, suggesting that there is not a genetic predisposition of one of these cultivars toward a higher or lower variance-to-mean-yield ratio. This finding is consistent with a previous study that reported no substantial differences in the coefficients of variation for four cultivars of strawberry grown in England (8).

Leaf number and crown diameter were positively correlated with yield during the first 2 months of the season but not for the rest of the season. Fruit produced in the later part of the season make a larger contribution to total yields than fruit produced in the early part of the season; therefore, correlation between cumulative fruit yield and growth traits was relatively low or not significant. A reduction in the effect of transplant size on yield has been observed when yields for perennial strawberry were examined over successive seasons (10). However, there was no change in effect of transplant size on yield over time during the same growing season. The lack of correlation between transplant size and yield in the later part of the growing season in Florida may be a result of the relatively long period of time plants are productive in the annual culture system. Variation in the measured growth traits accounted for less than $7 \%$ of the variation in cumulative seasonal yield. Therefore, selection of plants for uniform growth characteristics is unlikely to enhance experimental precision for whole-season measurements of yield. However, information regarding the effect of transplant growth characteristics on the timing of fruit production may be of interest to growers, because early-season fruit from Florida is sold at higher prices. Plant growth characteristics also had little or no correlation with total disease incidence, indicating that selection of plants having uniform growth characteristics would do little to enhance the efficiency of experiments examining treatment effects on disease incidence.

\section{ACKNOWLEDGMENTS}

We thank J. Sumler for helping conduct this research and C. Manley for assisting in the preparation of this manuscript.

\section{LITERATURE CITED}

1. Anderson, W. C. 1979. Alley effect in border rows of green pea plots and its reduction through planting barley guard rows. Hortscience 14:530-531.

2. Bartlett, M. S. 1947. The use of transformations. Biometrics 3:39-52.

3. Berger, R. D. 1975. Disease incidence and infection rates of Cercospora apii in plant spacing plots. Phytopathology 65:485-487.

4. Chandler, C. K., Albregts, E. E., Price, J. F., and Crocker, T. E. 1994. Growing strawberries in Florida: Guidelines for the 1994-1995 season. Citrus Veg. Mag. (Aug.):10-14.

5. Chanter, D. O. 1975. Modifications of the angular transformation. Appl. Stat. 24:354359 .

6. Hatheway, W. H. 1958. Convenient plot size. Agron. J. 53:279-280.

7. Hatheway, W. H., and Williams, E. J. 1958. Efficient estimation of the relationship between plot size and the variability of crop yields. Biometrics 14:207-222.

8. Holland, D. A. 1971. Variability in the yield of strawberries. J. Hortic. Sci. 46:55-62.

9. Hollowell, E. A., and Heusinkveld, D. 1933. Border effect studies of clover and alfalfa. J. Am. Soc. Agron. 25:779-789.

10. Hughes, H. M. 1967. The effects of planting time, runner size and plant spacing on yield of strawberries. J. Hortic. Sci. 42:253-262.

11. Jarvis, W. R. 1980. Taxonomy. Pages 1-18 in: The Biology of Botrytis. J. R. Coley-Smith, K. Verhoeff, and W. R. Jarvis, eds. Academic Press, London.

12. Jarvis, W. R., and Borecka, H. 1968. The susceptibility of strawberry flowers to infection by Botrytis cinerea. Hortic. Res. 8:147154.

13. Johnson, K. B., and Powelson, M. L. 1983. Analysis of spore dispersal gradients on Botrytis cinerea and gray mold disease gradients in snap beans. Phytopathology 73:741746.

14. Legard, D. E., and Chandler, C. K. 2000. Evaluation of fungicides to control Botrytis fruit rot of strawberry, 1998. Fungic. Nematicide Tests 55:124-125.

15. Legard, D. E., Mertely, J. C., and Chandler, C. K. 2001. Reduced application rate and scheduling of fungicides for control of Botrytis fruit rot on annual strawberry. (Abstr.) Phytopathology 91:S54.

16. Legard, D. E., Widden, A. J., and Chandler, C. K. 1997. Incidence and occurrence of straw- berry diseases in Florida from 1991-1996. Adv. Strawberry Res. 16:35-47.

17. Legard, D. E., Xiao, C. L., Mertely, J. C., and Chandler, C. K. 2000. Effects of plant spacing and cultivar on incidence of Botrytis fruit rot in annual strawberry. Plant Dis. 84:531-538

18. Legard, D. E., Xiao, C. L., Mertely, J. C., and Chandler, C. K. 2001. Management of Botrytis fruit rot in annual winter strawberry using captan, thiram and iprodione. Plant Dis. 85:31-39.

19. Lin, C. S., and Binns, M. R. 1986. Relative efficiency of two randomized block designs having different plot sizes and numbers of replications and of plots per block. Agron. J. 78:531-534.

20. Madden, L. V., and Hughes, G. 1995. Plant disease incidence: Distributions, heterogeneity, and temporal analysis. Annu. Rev. Phytopathol. 33:529-564.

21. Mason, D. T. 1987. Effects of initial plant size on the growth and cropping of strawberry (Fragaria $X$ ananassa Duch.). Hortic. Res. 27:31-47.

22. Mertely, J. C., Chandler, C. K., Xiao, C. L., and Legard, D. E. 2000. Comparison of sanitation and fungicides for management of Botrytis fruit rot of strawberry. Plant Dis. 84:1197-1202.

23. Mertely, J. C., MacKenzie, S. J., and Legard, D. E. 2002. Timing of fungicide applications for Botrytis cinerea based on development stage of strawberry flowers and fruit. Plant Dis. 86:1019-1024.

24. Neter, J., Wasserman, W., and Kutner, M. H. 1990. Applied Linear Statistical Models. 3rd ed. Irwin, Boston.

25. Pearce, S. C. 1976. An examination of Fairfield Smith's law of environmental variation. J. Agric. Sci. 87:21-24.

26. Powelson, R. L. 1960. Initiation of strawberry fruit rot caused by Botrytis cinerea. Phytopathology 50:491-494.

27. Smith, H. F. 1938. An empirical law describing heterogeneity in the yield of agricultural crops. J. Agric. Sci. 28:1-23.

28. Sommer, N. F., Fortlage, R. J., Mitchell, F. G., and Maxie, E. C. 1973. Reduction of postharvest losses of strawberry fruits from gray mold. J. Am. Hortic. Sci. 98:285-288.

29. Sproat, B. B., Darrow, G. M., and Beaumont, J. H. 1936. Relation of leaf area to berry production in strawberry. Proc. Am. Soc. Hortic. Sci. 33:389-392.

30. Stapleton, S. C., Chandler, C. K., Legard, D. E., Price, J. F., and Sumler, J. C. 2001. Transplant source affects fruiting performance and pests of 'Sweet Charlie' strawberry in Florida. Hortechnology 11:61-65.

31. Swallow, S. C., and Wehner, T. C. 1986. Optimum plot size determination and its application to cucumber yield trials. Euphytica 35:421-432.

32. Taylor, L. R. 1961. Aggregation, variance and the mean. Nature 189:732-735.

33. Turechek, W. W., Ellis, M. A., and Madden, L. V. 2001. Sequential sampling for incidence of Phomopsis leaf blight of strawberry. Phytopathology 91:336-347.

34. Turechek, W. W., and Madden, L. V. 1999. Spatial pattern analysis and sequential sampling for the incidence of leaf spot on strawberry in Ohio. Plant Dis. 83:992-1000.

35. Wehner, T. C. 1987. Efficient methods for testing vegetable cultivars. Hortscience 22:1220-1223

36. Weiner, J. 1990. Plant population ecology in agriculture. Pages 235-262 in: Agroecology. C. R. Carroll, J. H. Vandermeer, and P. M. Rossett, eds. McGraw-Hill, New York. 